\title{
Mapping Information Wealth and Poverty: The Geography of Gazetteers
}

\author{
Mark Graham and Stefano De Sabbata \\ Oxford Internet Institute, University of Oxford \\ mark.graham@oii.ox.ac.uk stefano.desabbata@oii.ox.ac.uk
}

Pre-print of the following paper: Graham, M. and De Sabbata, S. 2016. Mapping Information Wealth and Poverty: The Geography of Gazetteers. Environment and Planning $A$. (in press).

\begin{abstract}
Gazetteers are dictionaries of geographic placenames that have important implications far beyond the worlds of geographers and cartographers. By containing 'definitive' lists of places, gazetteers have the ontological power to define what will and won't be geocoded and represented in databases, maps, search engines, and ultimately our spatial understandings of place.
\end{abstract}

This paper focuses attention on GeoNames, which is the world's largest freely available and widely used gazetteer. We illustrate how content in GeoNames is characterised by highly uneven spatial distributions. There are dense clusters of placenames in some parts of the world and a relative absence of geographic content in others. These patterns are related to not just the wealth and population-size of a country, but also its policies on internet access and open data. The paper then traces some of the specific implications of this information inequality: showing how biases in gazetteers are propagated in a variety of geographic meaning-making. 


\section{The Ontological Power of Gazetteers}

Gazetteers play an often understated role in our contemporary informationalised lives and economies. In containing a dictionary of placenames, they offer the informational canvas from which a huge variety of geographic meaning is made, thus playing "a vital role in information systems" (Goodchild and Hill, 2008).

Traditionally, gazetteers have been used as an index that lists features, characteristics, and statistics that can all be linked to particular places. The ancient Egyptians, for instance, in each administrative unit, documented the names of capitals, sacred trees, local gods, and other data of interest (Wilson 2003). Leaders or administrators consulting the gazetteer would then know where things are, their characteristics, and how to find, pronounce, spell, or describe them. The Greeks under Alexander, the English under William I, the Mughals under Akbar, and many other societies around the world needed structured geographic information in order to effectively govern (c.f. Tarn 1923; Bates 1985). These uses of gazetteers have persisted until the present day.

But the power of gazetteers has been amplified in the contemporary moment for two key reasons. First, because of the 'data revolution' and the exponential growth in the availability of information about most facets of everyday life (Kitchin 2014; Graham and Shelton 2013), we have seen a synergistic cycle between the presence and use (or supply and demand) of geographic data (Graham 2013). Within the context of this datafication $^{1}$ of everything, the need to geographically locate secondary datasets (like news or social media) becomes ever more important. Think, for instance, of different

\footnotetext{
1 i.e. a trend in which various facets of everyday life are turned into digital data from which value can be extracted (Mayer-Schonberger and Cukier 2013)
} 
types of free text (websites, blog posts, digitised books, social media etc.) that can be linked, in a structured way, to geographic entities in order to perform further analysis or draw further meaning from the datasets. Gazetteers are needed for this linking, structuring, and meaning-making to happen.

Second, ever more of the information we use and rely on is mediated through complex assemblages of algorithms, ranking systems, datasets, application programming interfaces, and more informal database mashups. In other words, the information that people use for any particular service is ever less likely to be selfcontained in any one particular dataset. Instead, what happens is that information is linked between a range of datasets, mediated by a variety of rules and algorithms, and often served up in a bespoke and ephemeral form. Gazetteers are essential to much of this informational linking ${ }^{2}$ and remixing, as they offer the 'ground truth' needed to geolocate content that pings around the web (cf. Lemmens and Keßler (2014)).

By presenting lists of structured information about the world, gazetteers have always had the power to shape and structure how geographic meaning is made. The inherent biases of gazetteers necessarily influence how we are able to understand all sorts of other data that augments our lives. As such, because of the importance and ontological power of gazetteers, it is important to better understand the specific biases embedded into them. To do this we map the world's largest freely available gazetteer: GeoNames.

\footnotetext{
2 Recent years have seen the raise of a set of best practices for publishing and connecting structured data, commonly referred to as Linked Data (Bizer et al, 2009)
} 


\section{The GeoNames gazetteer}

The GeoNames gazetteer has grown to be a pivotal tool in many fields of geographic research as it offers a free, open, world-wide list of placenames. Data that we used were obtained from the GeoNames gazetteer 'data dump'3 in May 2013. The gazetteer is put together based on freely available national gazetteers and datasets ${ }^{4}$, as well as crowdsourced content, commonly referred to as volunteered geographic information (VGI) (see e.g., Goodchild 2007, Haklay 2010, Graham 2011a, Ostermann 2011, Elwood et al. 2012). This means that, in theory, anybody can enter data, suggest new placenames, and edit existing content.

Figure 1 illustrates the global density of placenames listed in GeoNames. The pixel colours represent the number of placenames (i.e., names referring to a geographic place) per square kilometre. The image was created using the Point Density ArcGIS tool, calculating the density of features representing placenames in the full GeoNames data dump, using squared units of $10 \mathrm{~km}$ per side (the neighbourhood being composed by the same single cell unit). All maps here presented classify values in six quantiles, dividing the highest and the lowest quartiles in two, to highlight the highest and the lowest $10 \%$ of values. However, in Figure 1, the lowest non-zero value (where only one placename was found per unit) is shared by $25.3 \%$ of units, and thus the lowest $10 \%$ quantile is not shown separately.

In order to explore an assumption that more densely populated areas would be represented by a higher density of placenames, Figure 2 illustrates the ratio between number of placenames and population. Population data used in this map were 
obtained from the Socioeconomic Data and Applications Center (SEDAC) (2014).

We used the most detailed version of world-wide population data from SEDAC, which uses a half degree of latitude by half a degree of longitude resolution. This conditioned the subsequent analysis and visualizations, as the number of placenames in GeoNames have been aggregated at the same level of detail.

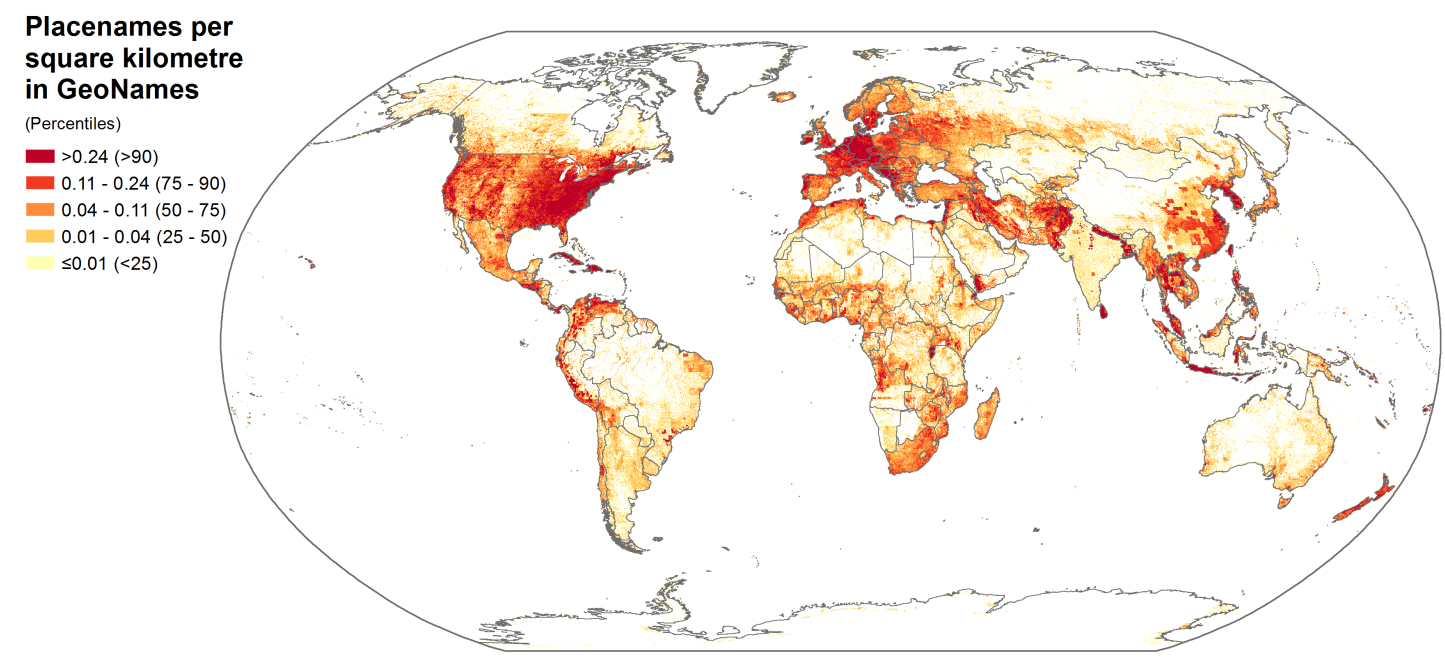

Figure 1: Spatial distribution of placenames in the GeoNames gazetteer
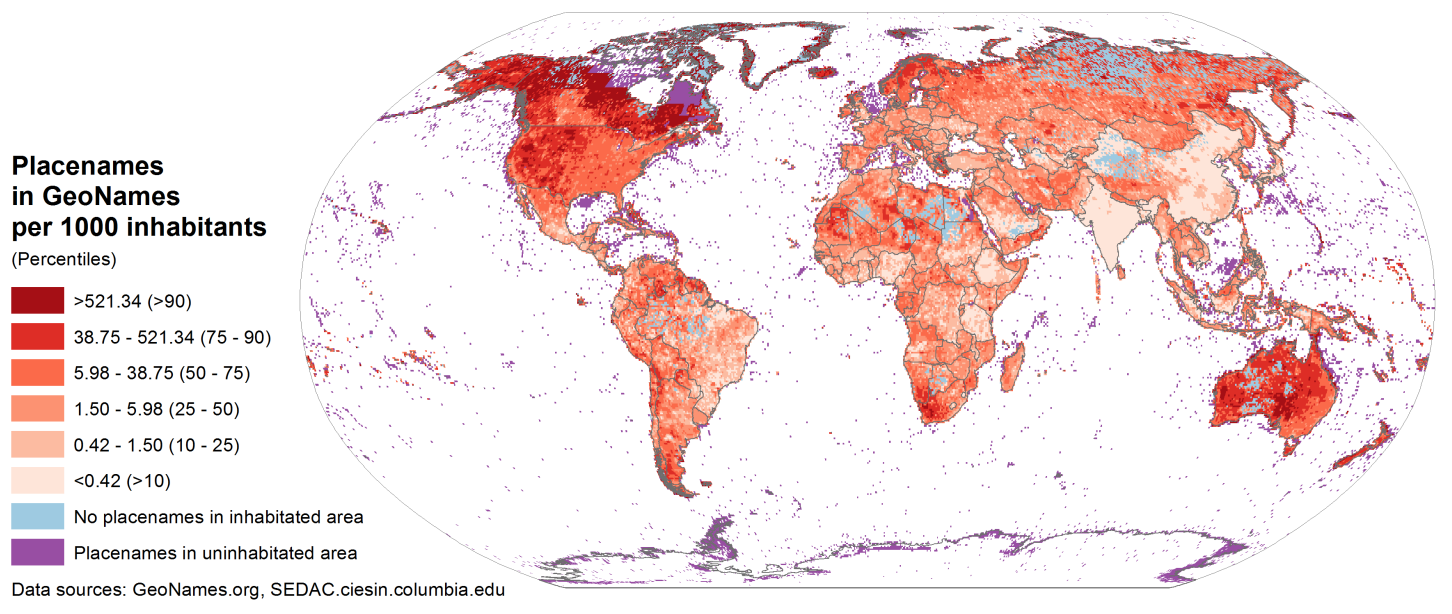

Figure 2: Spatial distribution of placenames in the GeoNames gazetteer compared to the spatial distribution of the population 
Figure 3 narrows the comparison to the placenames included in the smaller 'cities1000' data dump, which includes only placenames referring to places with more than 1000 inhabitants, or seats of administrative division ${ }^{5}$, which is frequently used when a geocoding procedure is limited to cities and towns (e.g., geocoding the home location specified by social media users in their profile). In other words, this map excludes placenames about features like forests, mountains, rivers, and tiny settlements.

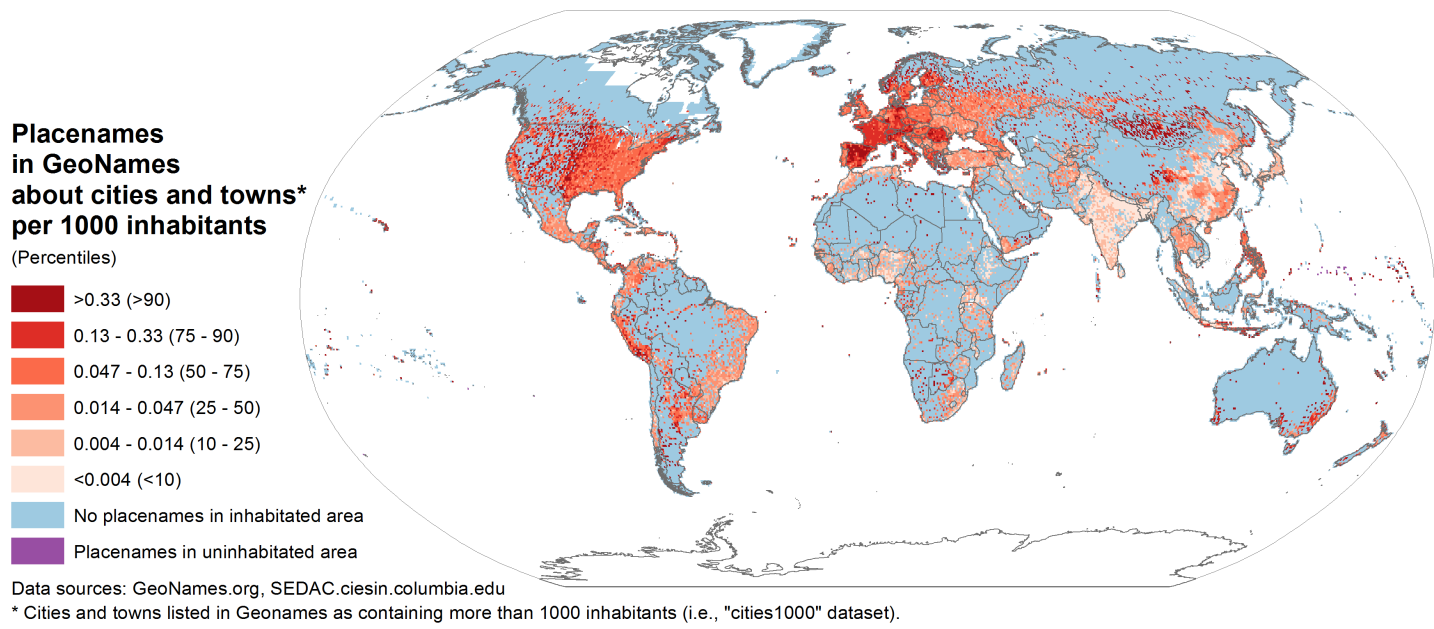

Figure 3: Spatial distibution of placenames in GeoNames included in the dataset of populated places with more than a thousand inhabitants, compared to the spatial distribution of population

Figure 4 illustrates the population density in the areas where GeoNames contains no placenames with detailed information about the related number of inhabitants. This map therefore shows us parts of the world that are populated, but are have no population information within the gazetteer. Figure 3 and 4 thus illustrate which parts of the world population are less represented, or not represented, within the data contained within the gazetteer.

Finally, Figure 5 illustrates the number of placenames in GeoNames per country compared to 2012 population data from the World Bank ${ }^{6}$ : showing the relationship between population and information density as well the outliers. These estimates are

\footnotetext{
${ }^{5}$ download.geonames.org/export/dump/readme.txt ${ }^{6}$ data.worldbank.org
} 
employed for the country-based comparison, as the most recent data from SEDAC (at the time of analysis, and excluding projected "future estimates") refer to the year $2000^{7}$.
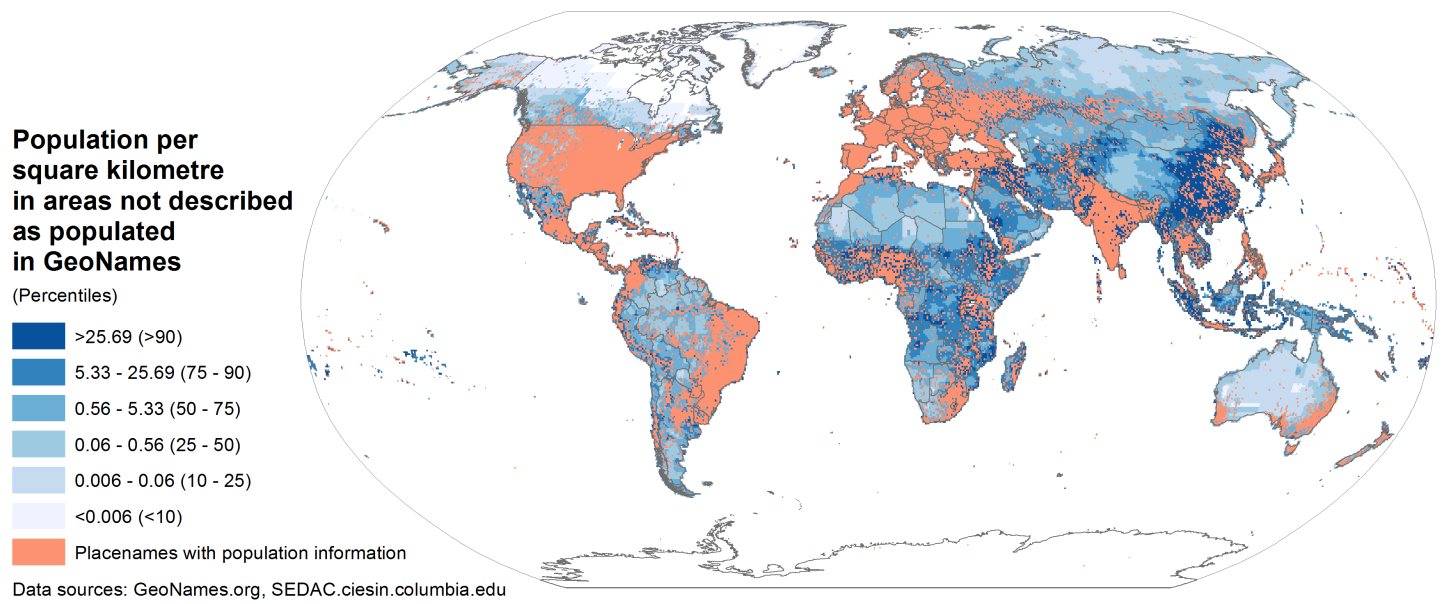

Figure 4: Population density in areas where GeoNames lists no placename with detailed information about the related population

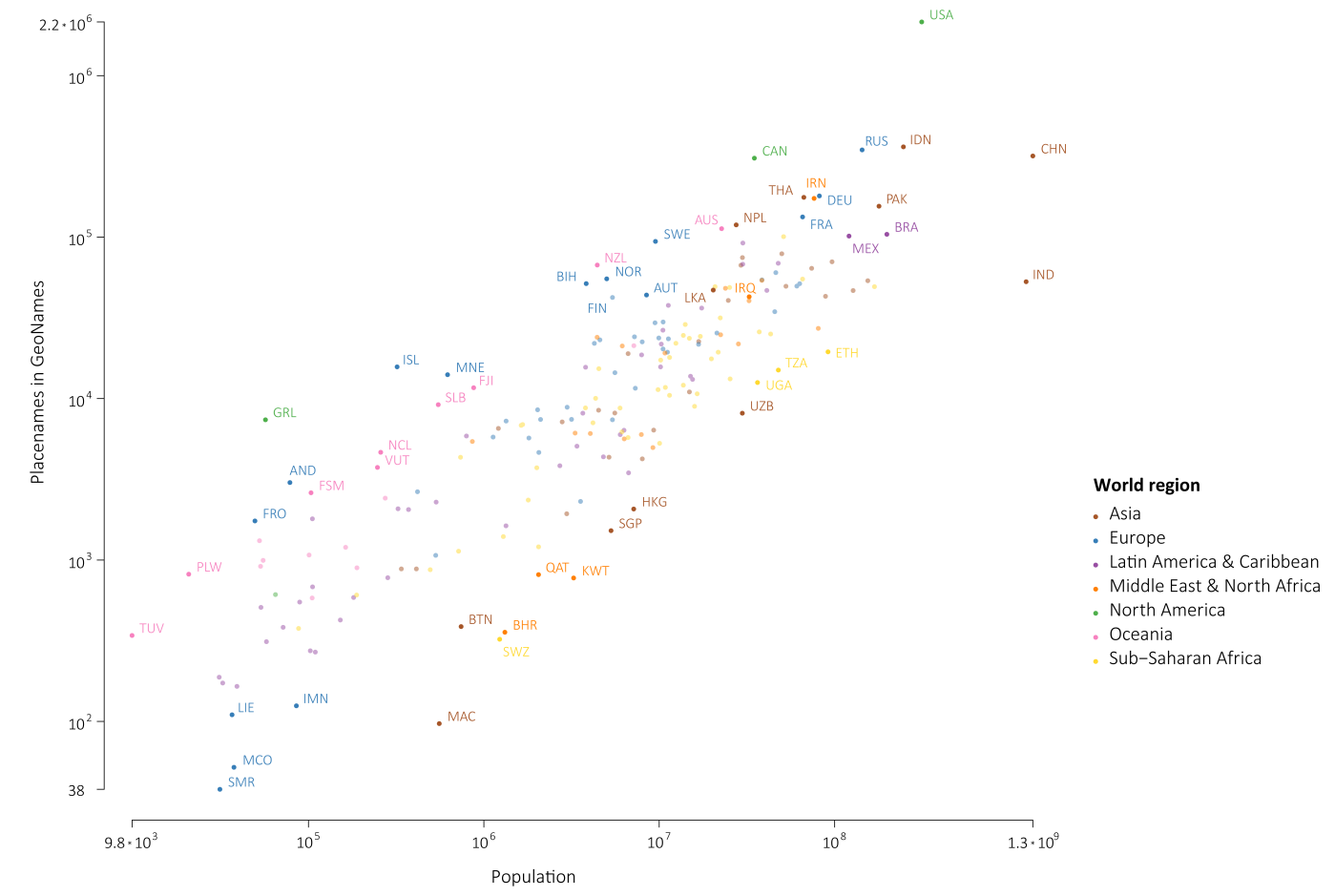

Figure 5: Comparison between number of placenames in GeoNames per country and country population

${ }^{7}$ sedac.ciesin.columbia.edu/data/collection/gpw-v3/methods/method1 


\section{Uneven Geographies}

Our analysis shows that the spatial distribution of the gazetteer is not a simple mirror of the geography of population (see Figure 1). Nor are placenames evenly distributed among regions and countries. Instead, we see dense clusters of placenames in some parts of the world and a lack of geographic information in others. Interestingly, the information presences that we see are characterized by unusual patterns.

The United States accounts for over a quarter of the entire database. This means that there is more content created about the United States than all of Asia combined (Asia accounts for only about $23 \%$ of placenames, despite being home to well over half the world's population). There is also more content in the United States than all of Europe combined (Europe accounts for about $19 \%$ of placenames).

More surprising is the fact that Indonesia and Russia are the second and third most well-annotated countries in the world. They each account for about $4 \%$ of the collection. China then follows with $3.8 \%$ of placenames. This figure is only slightly more than Canada, even though the population of China is about 39 times larger than that of Canada. India is by far the most underrepresented country in the world. It hosts only $0.6 \%$ of the collection, despite representing over $17 \%$ of the world's population.

Together, the ten most described countries are home to more than half of the collection. This means that $35 \%$ of the world's landmass and $36 \%$ of the world's population are represented by a majority of content in one of the world's most used geographic dictionaries. Figures 2 and 5 show the relationship between population and geographic content in more detail. If we exclude small countries ${ }^{8}$, a log-log

\footnotetext{
${ }^{8} 34$ countries with less than 250,000 inhabitants were excluded from the analysis in order to obtain normally distributed values for the natural logarithm of population, used as independent variable.
} 
regression model suggests a positive relation between number of placenames and population, where the latter accounts for $63 \%$ of the variation in the number of placenames per country.

National and international policies seem to play a large role in the construction of this gazetteer. For instance, Nepal is ranked $11^{\text {th }}$ in terms of content, apparently thanks to a project funded by the European Union in 2001 (Budhathoki and Chhatkuli, 2004), and contains more placenames than India and the UK put together. Iran contains almost the same number of placenames as Germany. North Korea and Sri Lanka are described in almost as much detail as Austria. However, although many German and Austrian government institutions can be found in the list of GeoNames's primary data sources $^{9}$, no equivalent institutions from Iran, North Korea, or Sri Lanka are listed. This disparity is also probably not due to a significant discrepancy in the amount of VGI content generated by users from those regions (i.e. because of internet penetration rates and censorship regimes, it is a reasonable assumption to make that there should be fewer 'user-generated' contributions coming from North Korea versus Austria).

Instead, we speculate that some of these patterns exist due to the fact that the National Geospatial-Intelligence Agency's (NGA) and the United States Board on Geographic Names are the sources of many placenames outside the United States and Canada. Created as part of the U.S. intelligence service, the strategy of the NGA is to provide "support to military and intelligence operations, intelligence analysis, homeland defense, and humanitarian and disaster relief" ${ }^{\prime \prime}$. These objectives likely explain why

\footnotetext{
${ }^{9}$ geonames.org/data-sources.html

10 www1.nga.mil/About/NGAStrategy/Pages/default.aspx
} 
we see particular informational focus is placed on locations like Iran, North Korea, and Sri Lanka.

There are also indications that a significant amount of content has been created by 'crisis mappers'. The amount of information created about Haiti in particular appears to be a reflection of the intense effort that went into mapping the country after its 2010 earthquake (Zook et. al. 2010).

When only looking at geographic information about populated places (see Figures 3 and 4), we see the highest proportions of placenames to population in Europe and the lowest in Africa and Asia. Large (populated) parts of China, for instance, have no placenames describing them (see Figure 4). India, in contrast, has placenames about a lot of the country: but still a much lower density than can be observed in Europe and North America.

\section{Conclusions}

The geography of gazetteers can have far-reaching implications. Gazetteers are an increasingly important informational tool in contemporary information infrastructures. For instance, they are used by most "name entity recognition" software to identify placenames, by machine learning algorithms (Leidner and Lieberman, 2011) to disambiguate placenames (Buscaldi, 2011), and are employed to assign geographical references to identified placenames (Schlieder and Henrich, 2011). More generally, these tools and are used by an increasing number of services, search engines, and apps to grasp the geographies of documents and webpages, and thus to aid our search for, and interaction with, geographic information through services like Google and Facebook. 
Because of the key role that gazetteers play in underpinning and shaping informationbased services that are crucial to a lot of contemporary activities, there is significant potential for both virtuous and vicious informational cycles. By not appearing in gazetteers, places (or placenames) are unable to be identified in textual analysis, and those places then vanish from outcome geocoded datasets. Those outcome geocoded datasets could be used as inputs for further analysis: perpetuating a cycle of geographic visibility and invisibilty (see also Bowker, 2013). Hence, by not appearing in the gazetteers in first instance, some places are unlikely to ever become visible in digital and geocoded information; and because so much additional research, analysis, and visualisation relies on using large gazetteers, the biases that we see here are only likely to be propagated throughout the webs of knowledge. In many ways, gazetteers are thus the gatekeepers to the digital presence of places.

In sum, issues highlighted in previous work on gazetteers (such as Brunner et al. 2008), such as the fact that they paint selective geographic pictures, are seen again in our maps. These visualizations demonstrate that the process of opening up large platforms to crowdsourcing doesn't seem to lessen inequalities in the geographies of information (see also Graham et. al. 2015; Graham 2014). There are even further indications that GeoNames data are far less precise in poor countries than in rich ones (c.f. Ahlers 2013).

Sometimes biases in the geographies of information that annotate and represent our world are blatant and easily discoverable (e.g. Graham 2011b; Hecht 2009; Graham, Hale, and Stephens 2013). However, it is crucial to remember that, when working with large datasets, our ability to even make meaning from that information will be constrained if the very datasets that we use to geolocate content are themselves 
characterised by significant bias. As ever more of our lives are augmented by digital information, it therefore remains imperative to better understand the ontological power of gazetteers and the ways in which their content can ripple through into both digital representations of our world and digitally-mediated practices.

\section{References}

Ahlers D, 2013 "Assessment of the accuracy of GeoNames gazetteer data" Proceedings of the 7th Workshop on Geographic Information Retrieval

Bates D, 1985, "A Bibliography of Domesday Book". Woodbridge: Boydell.

Bizer C, Heath T, and Berners-Lee T, 2009, "Linked data-the story so far." International journal on semantic web and information systems, 5(3) 1-22

Bowker G C, 2013, “Data flakes: An afterword to 'Raw Data' is an oxymoron: Raw data is an oxymoron". Cambridge, Mass.: MIT Press.

Brunner T, Purves RS, Weibel R, 2008, “Geographic Information Retrieval: Identifikation der geographischen Lage von Zeitungsartikeln'”, Master's thesis, Geographisches Institut der Universität Zürich, Switzerland

Budhathoki N R, Chhatkuli R R, 2004, "Building geographic information infrastructure at national level: Nepalese experience", GSDI 7 th Conference, Bangalore 
Buscaldi D, 2011, “Approaches to disambiguating toponyms.” SIGSPATIAL Special 3(2) 16-19

Elwood S, Goodchild M F, Sui D Z, 2012, "Researching volunteered geographic information: Spatial data, geographic research, and new social practice." Annals of the Association of American Geographers, 102(3) 571-590

Goodchild M F, 2007, “Citizens as sensors: the world of volunteered geography." GeoJournal, 69(4) 211-221

Goodchild M F, 2013, “The quality of big (geo) data”, Dialogues in Human Geography, 3(3) 280-284

Goodchild M F, Hill L L, 2008, "Introduction to digital gazetteer research." International Journal of Geographical Information Science, 22(10) 1039-1044

Graham M, 2011a, “Cloud Collaboration: Peer-Production and the Engineering of the Internet", in Engineering Earth Ed. Brunn S (Springer, New York) pp 67-83 Graham M, 2011b, "Wiki Space: Palimpsests and the Politics of Exclusion", in Critical Point of View: A Wikipedia Reader, Eds. Lovink G, Tkacz N (Institute of Network Cultures, Amsterdam) pp 269-282

Graham M, 2013, "The Virtual Dimension”, in Global City Challenges: debating a concept, improving the practice, Eds. Acuto M, Steele W, (Palgrave, London) pp $117-139$

Graham M, Shelton T, 2013, “Geography and the Future of Big Data; Big Data and the Future of Geography", Dialogues in Human Geography, 3(3) 255-261 
Graham M, Hale S, Stephens M, 2013, “Geographies of the World's Knowledge London", Convoco! Edition

Graham M, Hogan B, Straumann R K, Medhat A, 2015, "Uneven Geographies of User-Generated Information: Patterns of Increasing Informational Poverty", Annals of the Association of American Geographers (forthcoming).

Graham M, 2014, "Internet Geographies: Data Shadows and Digital Divisions of Labour", in Society and the Internet: How Networks of Information and Communication are Changing our Lives, Eds. Graham M, Dutton W H (Oxford University Press, Oxford) pp 99-116.

Haklay M, 2010, "How good is volunteered geographical information? A comparative study of OpenStreetMap and Ordnance Survey datasets." Environment and planning. B, Planning \& design, 37(4) 682.

Hecht B, Gergle D, 2009, "Measuring Self-Focus Bias in Community-Maintained Knowledge Repositories", Proceedings of the 2009 International Conference on Communities and Technologies , pp. 11-19

Lemmens R, Keßler C, 2011, “Geo-Information Visualizations of Linked Data”, Proceedings of the 17th AGILE Conference on Geographic Information Science (AGILE)

Leidner J L, Lieberman M D, 2011, “Detecting geographical references in the form of place names and associated spatial natural language",SIGSPATIAL Special 3(2) 5-11 
Mayer-Schonberger V, Cukier K, 2013, Big Data: A Revolution That Will

Transform How We Live, Work, and Think (Eamon Dolan/Houghton Mifflin Harcourt)

Ostermann F 0, Spinsanti L, 2011, “A conceptual workflow for automatically assessing the quality of volunteered geographic information for crisis management." Proceedings of AGILE

Schlieder C, Henrich A, 2011, "Spatial grounding with vague place models." SIGSPATIAL Special 3(2) 20-23.

SEDAC. Center for International Earth Science Information Network - CIESIN Columbia University, and Centro Internacional de Agricultura Tropical - CIAT. 2005. Gridded Population of the World, Version 3 (GPWv3): Population Density Grid. Palisades, NY: NASA Socioeconomic Data and Applications Center (SEDAC). http://dx.doi.org/10.7927/H4XK8CG2. Accessed 15 July 2014.

Tarn W W, 1923, “Alexander and the Ganges," The Journal of Hellenic Studies 43(2) 93-101

Wilson P, 2003, Sacred Signs: Hieroglyphs in Ancient Egypt (Oxford University Press, Oxford)

Zook M, Graham M, Shelton T, Gorman S, 2010, “Volunteered Geographic Information and Crowdsourcing Disaster Relief: A Case Study of the Haitian Earthquake", World Medical and Health Policy, 2(2) 7-33 